\section{(2) OPEN ACCESS}

${ }^{1}$ Epidemiology, School of Public Health, University of Alabama at Birmingham, Birmingham, Alabama, USA

${ }^{2}$ Division of Infectious Diseases, School of Medicine, University of Alabama at Birmingham, Birmingham, Alabama, USA ${ }^{3}$ Disease Control, Jefferson County Department of Health, Birmingham, Alabama, USA

Correspondence to Dr Sadeep Shrestha, Epidemiology, University of Alabama at Birmingham, Birmingham, Alabama, USA sshresth@uab.edu

Received 11 March 2020 Revised 24 November 2020 Accepted 22 December 2020 Published Online First 12 January 2021

Check for updates

(C) Author(s) (or their employer(s)) 2022. Re-use permitted under CC BY-NC. No commercial re-use. See rights and permissions. Published by BMJ.

To cite: Ye $Y$,

Burkholder GA, Wiener $\mathrm{H}$

et al. Sex Transm Infect

2022:98:44-49.

\title{
HSV-infection-related herpetic anogenital ulcer disease among PLWH in southeastern US: electronic medical record based analysis
}

\author{
Yuanfan Ye, ${ }^{1}$ Greer A Burkholder, ${ }^{2}$ Howard Wiener, ${ }^{1}$ Stella Aslibekyan, ${ }^{1}$ Ashraf E Khan, ${ }^{3}$ \\ Sadeep Shrestha (D) ${ }^{1}$
}

Objectives The southeastern US is a domestic epicentre for incident HIV with high prevalence of herpes simplex virus (HSV) coinfection. We estimated the incidence rates (IR) of symptomatic herpetic anogenital ulcer disease (HAUD) and assessed its associations with demographic and clinical characteristics, specifically with immunological markers using median, nadir and trajectory CD4 counts.

Methods Electronic medical records (EMR) of over 7000 people living with HIV (PLWH) attending one of the leading HIV clinics in the southeastern US between 2006 and 2018 were reviewed and analysed. IR of HSV-related HAUD were estimated per 10000 person years. Joinpoint regressions were performed to examine temporal changes in the trends of IR. All IR and trends were stratified by gender and race. Six CD4 trajectory groups were constructed using the group-based trajectory modelling. Multivariable logistic models were conducted to assess the associations of CD4 counts (nadir, median CD4 and newly defined CD4 trajectory), separately with HAUD.

Results of the 4484 PLWH eligible individuals (3429 men, 1031 women and 24 transgender), we observed 425 patients with HSV-related HAUD. The mean $\log _{10}$ viral load was higher in HAUD than HAUD-free groups, whereas the median nadir CD4 count (cells/uL) was higher in the non-cases than the case groups $(p<0.05)$. HAUD were more frequent in women than men. Median CD4 ( $<200$ cell/uL) was associated with HAUD $(O R=2.1)$, but there were no significant associations with nadir CD4. Significant associations with declining and sustained low CD4 counts trajectory patterns were observed with HAUD.

Conclusions There were significant differences between men and women with incident HAUD among PLWH. EMR-based studies can provide innovative trajectory models that can potentially be helpful in guiding screening and clinical care of HAUD among highrisk PLWH.

\section{BACKGROUND}

Herpes simplex virus (HSV) is a common sexually transmitted infection (STI) in the general population, and it is more common among people living with HIV (PLWH). ${ }^{12}$ In the general US population, one in every five persons is infected with herpes simplex virus type 2 (HSV-2). ${ }^{3}$ It causes most of anogenital ulcer diseases (AUD); other major AUD include chancroid, syphilis and granuloma inguinale. ${ }^{3-5}$ In addition to HSV-2, approximately $17 \%$ of herpetic AUD (HAUD) is caused by herpes simplex virus type 1 (HSV-1). ${ }^{3}$ In the USA, HAUD continues to disproportionally burden blacks. Blacks contribute approximately $39.2 \%$ of the total HSV-2 infections with $48 \%$ of them being women. ${ }^{6}$ Previous findings have shown that PLWH coinfected with HSV-2 experience more frequent episodes of mucosal shedding of HSV-2 and more severe ulceration compared with immunocompetent people. ${ }^{7} \mathrm{~A}$ multisite prospective study, the Study to Understand the Natural History of HIV/ AIDS in the Era of Effective Therapy (SUN Study) reported that HSV-seroprevalence was three times greater among PLWH than the general US population, with $62 \%$ infected with HSV-2. ${ }^{9}$

It has been well recognised that chronic herpetic ulcers for more than 1-month duration is an AIDSdefining illness, ${ }^{10}$ but rate of incident herpes among PLWH in the combination antiretroviral therapy era (cART) is unclear. The trend of incident HAUD over the past decade has also not been reported in the context of universal cART administration.

Plasma CD4 T-cell count (CD4), a key immune indicator reflects the host's defensibility against pathogens, infections and illnesses, specifically among PLWH. ${ }^{11}$ Previous studies have demonstrated that PLWH with lower CD4 were more likely to develop HAUD. ${ }^{12}{ }^{13}$ CD4 counts are often characterised as nadir or median counts in the existing literature. ${ }^{14}{ }^{15}$ In contrast to measurements at a point during a defined period after HIV infection, CD4 count trajectory modelled from longitudinal data may be clinically more meaningful. To our knowledge, no studies have examined CD4 trajectory as predictors of incident HAUD and compared with nadir or median CD4 counts. We examined the trend of incident symptomatic HAUD and modelled its occurrence as a function of median, nadir and CD4 count trajectory over a 12-year follow-up among PLWH from an academic clinic in Alabama.

\section{METHODS}

\section{Study design and population}

Electronic health records between 1 January 2006 and 30 March 2018 from the University of Alabama at Birmingham (UAB) HIV clinic (locally known as 1917 Clinic) were reviewed. The UAB 1917 Clinic is the largest HIV clinic in the state of Alabama with 
extensive regional catchment and referral network, as previously described. ${ }^{16}{ }^{17}$ The prospective clinic cohort has collected more than 7000 patients' sociodemographic, behaviour, comorbidities, medications, vital signs, laboratory results and corresponding dates. Data were obtained by query of the cohort's electronic database using MS SQL Server 2008.

For the primary trend analysis, eligible patients were who: (1) visited the clinic at least twice for receiving primary HIV care during the 12-year study period and (2) were at least 18 years old at HIV diagnosis. CD4 trajectories were modelled based on the estimates from at least three CD4 examinations and restricted to those with at least three longitudinal CD4 measurements. Instead of using billing code such as ICD-9 code, the RISC database has established a standard clinical 'problem' sheet that collects and documents all diagnoses derived from patient medical charts recorded by the care providers. In our case, HAUD diagnoses were identified by the 1917 Clinic health providers and initially abstracted through the RISC database. Primary clinical manifestations of symptomatic HAUD include painful anogenital ulcers, dysuria, fever, dysuria, tender local inguinal lymphadenopathy and headache. Per the protocol, serological HSV tests are not required for the purpose of diagnosing symptomatic HAUD. ${ }^{18} 19$ This also corresponds to the current HAUD preventive strategies. Further, HAUD cases were verified by reviewing medical charts. For those patients who started receiving care from the HIV clinic before 1 January 2006, medical records were reviewed for up to prior 1 year, if available. Individuals with prevalent HAUD at baseline and/or during the 1 year prior (for those with medical records as described above), were excluded from the study. Thus, we were confident that eligible study participants were condition-free at baseline and that only incident conditions were identified during the follow-up period. Potential recurrent and refractory HAUD cases immediately linked to the cases identified during the follow-up would also be avoided in the context. All study participants were followed up until the first HAUD diagnosis (cases) or last clinical visit (HAUD-free controls). This present study was approved by the UAB Institutional Review Board.

\section{Statistical analysis}

\section{Cohort characterisation}

In univariate analysis, sociodemographic (gender, race and sexual orientation) and clinical characteristics (age at HIV diagnosis, age at study entry, nadir and median CD4 T cell counts and $\log _{10}$ viral load (VL)) were individually compared between HAUD (cases) and HAUD-free (control) patients. $\chi^{2}$ and t-tests were used to compare categorical and continuous variables between the diseased and disease-free group, respectively.

\section{Trend analysis}

Incidence rates (IR) (cases per 10000 person-years) were computed for HAUD compared between different genders (men vs women) and races (blacks vs whites). Annual IR was estimated followed by trend analyses using the Joinpoint Trend Analysis Software program (JTAS). ${ }^{20}$ Annual percentage change (APC) and average APC of trends were estimated. Detailed methods of the Joinpoint regression model were described in a previous study using the same cohort. ${ }^{21}$ nadir, median and trajectory CD4 count analysis

\section{Group-based trajectory modelling}

The group-based trajectory modelling (GBTM) approach identifies a finite number of groups of individuals exhibiting similar trajectories over a defined time of a single outcome. ${ }^{22}$ GBTM has two key components: identifying the polynomial order (shape) of the trajectory and determining a potential trajectory group for each patient in the data. ${ }^{22}$ Briefly, the selection process started with a model consisting of one group with the highest polynomial order allowed in the method (quartic degree) and added one group at a time until the best fitting model was found, as evidenced by the Bayesian information criterion (BIC). Subsequently, the polynomial order was reduced one at a time while a t-test was used to assess the fitness of each group to the polynomial order. Eventually, the lowest order with all significant groupings was determined and used as a new variable for multivariable regression.

The present study was derived from a clinical cohort, which had open enrolment instead of a unified study enrolment period. Under the primary analysis, patients would at least have two routine clinical visits and tested for $\mathrm{CD} 4$ counts during those two visits. In order to estimate and analyse CD4 counts trajectory, three time points of CD4 counts are required to meet statistical validity. Thus, we excluded the patients with less than three longitudinal CD4 tests. The initial numbers of CD4 tests data among patients eligible for GBTM varied between 3 and 44 during the follow-up after the exclusion. If all CD4 tests were used for grouping trajectories, discrepancies among the counts of CD4 tests would bring measurement variance towards the later period of the follow-up, because not all participants had stayed in the study for a full 12-year period. Therefore, the median count of CD4 tests for all participants was used for any model using CD4 count trajectories. To reduce the impact of random fluctuations, laboratory imprecision and incomplete model accuracy, ${ }^{23}{ }^{24} \mathrm{CD} 4$ series were square root-transformed in all subsequent analyses. Given the staggered entry due to different patients starting at different times, the starting point of each individual's follow-up was computed by subtracting each patient's enrolment date so each individual had a uniform start point in the analyses.

In addition to the statistical reasoning employed in GBTM, clinical context was considered in grouping CD4 count trajectory in our analyses. For example, an immunocompetent person without HIV-infection typically has a CD4 range between 500 and 1000 cells $/ \mu \mathrm{L} .{ }^{11}$ Likewise, PLWH with CD4 counts greater than $500 \mathrm{cells} / \mu \mathrm{L}$ are generally considered having good immune recoveries. Thus, consistent with prior literature, ${ }^{25}{ }^{26}$ in the current analysis, all trajectory CD4 counts at and above 500 cells $/ \mu \mathrm{L}$ were grouped into one trajectory.

Based on the BIC, $p$ values and the consideration for clinical interpretation of the CD4 counts, described above, the best fitting model for GBTM consisted of six CD4 trajectory groups with a linear order for incident HAUD. Group membership (\% of total study population in each trajectory group) and group morbidity (\% of HAUD in each trajectory group) were estimated.

In the subanalysis, multivariable regression models were used to compare the association of different forms of CD4 count and onset of HAUD. All statistically significant sociobehavioural factors from the univariate analysis and another important HIV-disease prognostic indicator, VL were controlled for in multivariable models. Different CD4 measures were tested for multicollinearity. The variance inflation factors (VIF) demonstrated that at least two of the three CD4 measures were highly correlated (VIF >2.4). Both sets of models tested nadir CD4 and median CD4 counts and CD4 count trajectory separately and were adjusted for race, age at HIV diagnoses and study entry and mean $\log _{10}$ VL. Furthermore, self-reported sexual orientation was highly correlated with gender (Pearson 
Table 1 Sociobehavioural and clinical characteristics of the study population $(n=4341)$

\begin{tabular}{|c|c|c|c|}
\hline Characteristics & $\begin{array}{l}\text { With anogenital } \\
\text { HSV-related ulcers } \\
(n=425)\end{array}$ & $\begin{array}{l}\text { No HSV-related ulcers } \\
(\mathrm{n}=3916)\end{array}$ & $P$ value \\
\hline Age at baseline* & $39.3(31.7-46.0)$ & $41.1(31.8-48.8)$ & 0.006 \\
\hline $\begin{array}{l}\text { Age at HIV } \\
\text { diagnosis* }\end{array}$ & $30.1(24.8-36.9)$ & $33.3(26.5-41.3)$ & $<0.0001$ \\
\hline Age at HAUD* & $43.1(35.2-50.4)$ & -- & \\
\hline Race & & & 0.167 \\
\hline Black & $262(61.7)$ & $2318(59.2)$ & \\
\hline White & $153(36.0)$ & 1435 (36.6) & \\
\hline Others & $10(2.3)$ & $163(4.2)$ & \\
\hline $\begin{array}{l}\text { Median years of } \\
\text { follow-up }\end{array}$ & $2.9(0.8-6.1)$ & $4.6(2.2-8.5)$ & $<0.0001$ \\
\hline Gender & & & $<0.0001$ \\
\hline Male & $273(64.2)$ & 3060 (78.14) & \\
\hline Female & $151(35.5)$ & $834(21.30)$ & \\
\hline Transgender & $1(0.3)$ & $22(0.56)$ & \\
\hline HIV risk factors & & & 0.044 \\
\hline MSM & $207(49.0)$ & 2030 (53.4) & \\
\hline Heterosexual & $187(44.2)$ & 1431 (37.6) & \\
\hline IVDU & $29(0.68)$ & $336(8.8)$ & \\
\hline Others & $0(0.0)$ & $6(0.2)$ & \\
\hline $\begin{array}{l}\text { Log }_{10} \text { VL (copies/ } \\
\mathrm{mL}) \dagger\end{array}$ & $4.8(5.2)$ & $4.7(5.3)$ & 0.23 \\
\hline $\begin{array}{l}\text { NadirCD4 (cells/ } \\
\mu \mathrm{L} \text { )* }\end{array}$ & $250(53-453)$ & $279(100-451)$ & 0.17 \\
\hline
\end{tabular}

*Median (IQR 25\%-75\%) is reported.

tMean (SD) is reported.

EHR, eletronic health records; HAUD, herpetic anogenital ulcer disease; IVDU,

intravenous drug users; MSM, men who have sex with men; VL, viral load.

$\rho=0.93)$. Therefore, we fit two separate sets of multivariable models: in addition to other covariates found significant in the univariate analyses, model 1 (M1) only included gender and model 2 (M2) only included sexual orientation. Survival analyses were first attempted using Cox proportional hazard regression. However, the Cox proportional hazards assumption could not be justified as the three CD4 counts metrics were heavily time dependent variables that did not produce constant HRs over time. Thus, logistic regression was used as an alternative method.

\section{RESULTS}

A total of 4803 PLWH attended the 1917 Clinic between 1 January 2006 and 30 March 2017 and 4341 PLWH met the inclusion and exclusion criteria. It was observed that $9.8 \%$ of the cohort were diagnosed with HAUD (table 1). Both ages at HIV diagnosis $(p<0.0001)$ and study participants $(p=0.0045)$ were younger among HAUD patients compared with HAUD-free patients. The median year of follow-up was also significantly shorter in patients with HAUD (2.9 years) than HAUD-free patients (4.6 years) $(p<0.0001)$. Women were likely to develop HAUD $(35.5 \%$ vs $21.3 \%$ in HAUDfree patients) $(\mathrm{p}<0.0001)$. Blacks were more likely to develop HAUD (61.7\% vs 59.2\%), but the difference was not statistically significant $(p=0.167)$. Patients with HAUD had higher proportion of heterosexuals (44.2\%) than HAUD-free patients $(37.6 \%)(\mathrm{p}=0.044)$.

A total of 273 and 151 HAUD diagnoses were identified over 20975.7 and 6965.9 years of follow-up among men and women, respectively (figure 1A). Among blacks and whites, 262 and 153 HAUD cases over a total of 17367.7 and 9813.1 years of follow-up, respectively, were diagnosed. IR was higher in women than men (216.8 vs 130.2 per 10000 person years; $\mathrm{p}<0.0001$ ) (figure 1A). However, no difference was observed between blacks and whites $(p=0.75)$ (figure 1B). Trends of HAUD were significantly different between men and women $(p=0.0004)$ (figure $1 \mathrm{~A})$ but not blacks and whites $(p=0.494)$ (figure 1B). There was a noticeable decrease between 2013 and $2016(\mathrm{APC}=38.4, \mathrm{p}=0.1)$ followed by an increase after 2016 (APC $=192, \mathrm{p}<0.0001$ ) in blacks and whites (figure 1B). This pattern was also observed in men (2013-2016: $\mathrm{APC}=44.2$, $\mathrm{p}=0.1 \mathrm{~L} ;$ 2016-2018: $\mathrm{APC}=250.1, \mathrm{p}<0.0001$ ) (figure 1A). However, no overall changes were statistically significant regardless of race ( $p=0.4$ both blacks and whites) or gender $(p=0.1$ for women, $p=0.4$ for men).
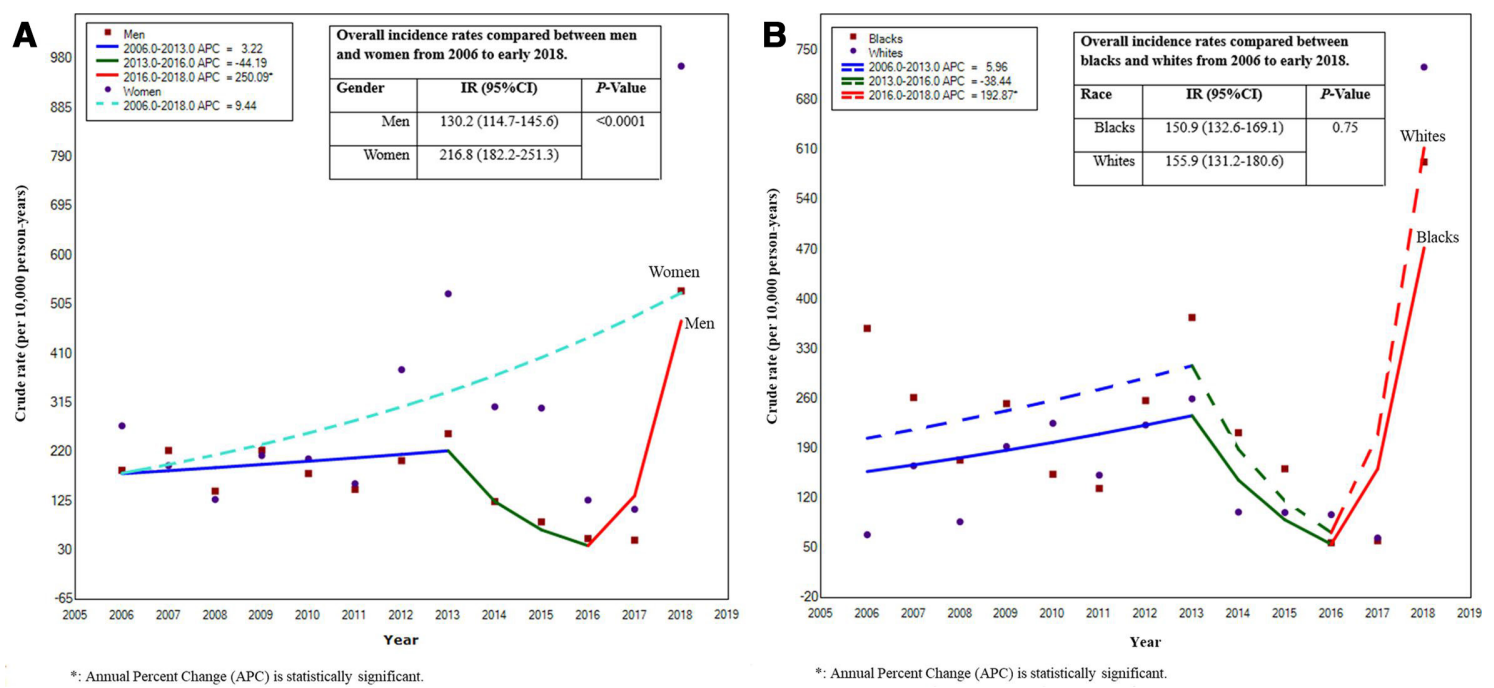

Figure 1 (A) Trend of incidence rate of HAUD between January 2006 and March 2018 compared between men (solid line) and women (dashed line). (B) Trend of incidence rate of HAUD between January 2006 and March 2018 compared between blacks (solid line) and whites (dashed line). HAUD, herpetic anogenital ulcer disease. 
Table 2 Associations between nadir, median and trajectory CD4 counts with anogenital ulcer disease (HAUD)

\begin{tabular}{|c|c|c|}
\hline Model 1 (n=3947) & OR $(95 \% \mathrm{Cl})$ & $P$ value \\
\hline \multicolumn{3}{|c|}{ Nadir CD4 group (cells/ $\mu L)$} \\
\hline$<200$ & 1.2 (0.8 to 1.7$)$ & 0.34 \\
\hline $200-500$ & 1.0 (0.8 to 1.3$)$ & 0.98 \\
\hline$\geq 500$ & Reference & \\
\hline \multicolumn{3}{|l|}{ Median CD4 group } \\
\hline$<200$ & 2.1 (1.5 to 3.0$)$ & $<0.0001$ \\
\hline $200-500$ & 1.3 (1.0 to 1.7$)$ & 0.052 \\
\hline$\geq 500$ & Reference & \\
\hline \multicolumn{3}{|l|}{ CD4 trajectory group } \\
\hline Group 1 & 2.6 (1.5 to 4.4$)$ & 0.0004 \\
\hline Group 2 & 1.3 (0.8 to 2.0$)$ & 0.24 \\
\hline Group 3 & $1.4(0.9$ to 2.0$)$ & 0.13 \\
\hline Group 4 & 2.5 (1.4 to 4.3$)$ & 0.0012 \\
\hline Group 5 & 1.2 (0.9 to 1.6$)$ & 0.27 \\
\hline Group 6 & Reference & \\
\hline \multicolumn{3}{|l|}{ Model 2 ( $n=3809)$} \\
\hline \multicolumn{3}{|c|}{ Nadir CD4 group (cells/ $\mu L)$} \\
\hline$<200$ & $1.3(0.9$ to 1.9$)$ & 0.16 \\
\hline $200-500$ & 1.0 (0.8 to 1.4$)$ & 0.74 \\
\hline$\geq 500$ & Reference & \\
\hline \multicolumn{3}{|l|}{ Median CD4 group } \\
\hline$<200$ & 2.3 (1.6 to 3.2$)$ & $<0.0001$ \\
\hline $200-500$ & 1.3 (1.0 to 1.7$)$ & 0.041 \\
\hline$\geq 500$ & Reference & \\
\hline \multicolumn{3}{|l|}{ CD4 trajectory group } \\
\hline Group 1 & $2.9(1.7$ to 5.0$)$ & $<0.0001$ \\
\hline Group 2 & $1.4(0.9$ to 2.2$)$ & 0.15 \\
\hline Group 3 & 1.5 (1.0 to 2.2$)$ & 0.066 \\
\hline Group 4 & 2.5 (1.4 to 4.5$)$ & 0.0018 \\
\hline Group 5 & 1.2 (0.9 to 1.6$)$ & 0.27 \\
\hline Group 6 & Reference & \\
\hline
\end{tabular}

Both models 1 and 2 were controlled for ages at baseline, HIV diagnosis, HAUD, median years of follow-up, gender and HIV risk factors.

HAUD, herpetic anogenital ulcer disease.

\section{CD4 count trajectory analysis}

Models 1 (M1, adjusted for gender) and 2 (M2, adjusted for sexual orientation) for HAUD included 3947 and 3809 subjects, respectively. Nadir CD4 count was not associated with the onset of new HAUD in both models (M1: $\mathrm{p}=0.44, \mathrm{M} 2: 0.2)$ whereas median (M1: $\mathrm{p}=0.0002, \mathrm{M} 2: \mathrm{p}<0.0001)$ and trajectory CD4 (M1: $\mathrm{p}=0.0033, \mathrm{M} 2: \mathrm{p}=0.0008)$ counts were statistically associated with incident HAUD. Participants with median CD4 counts less than 200 (cells $/ \mu \mathrm{L})$ were more likely to develop HAUD than the subjects with $\geq 500$ (cells $/ \mu \mathrm{L}$ ) (table 2 ). Among the six trajectory CD4 count series defined by the GBTM model (figure 2), individuals in group 1 with the lowest CD4 counts over the follow-up were most likely to have HAUD compared with group 6 (the highest CD4 trajectory) (table 2). Individuals in group 4 with a substantial decline in CD4 counts were also at elevated odds of incident HAUD compared with group 6 (table 2).

\section{DISCUSSION}

In the present study, among PLWH visiting a southeastern US HIV clinic between 2006 and 2018, the rate of HSV-related HAUD was greatly elevated among HIV-infected women compared with men, but no significant racial disparity was observed. The study
Anogenital Ulcers

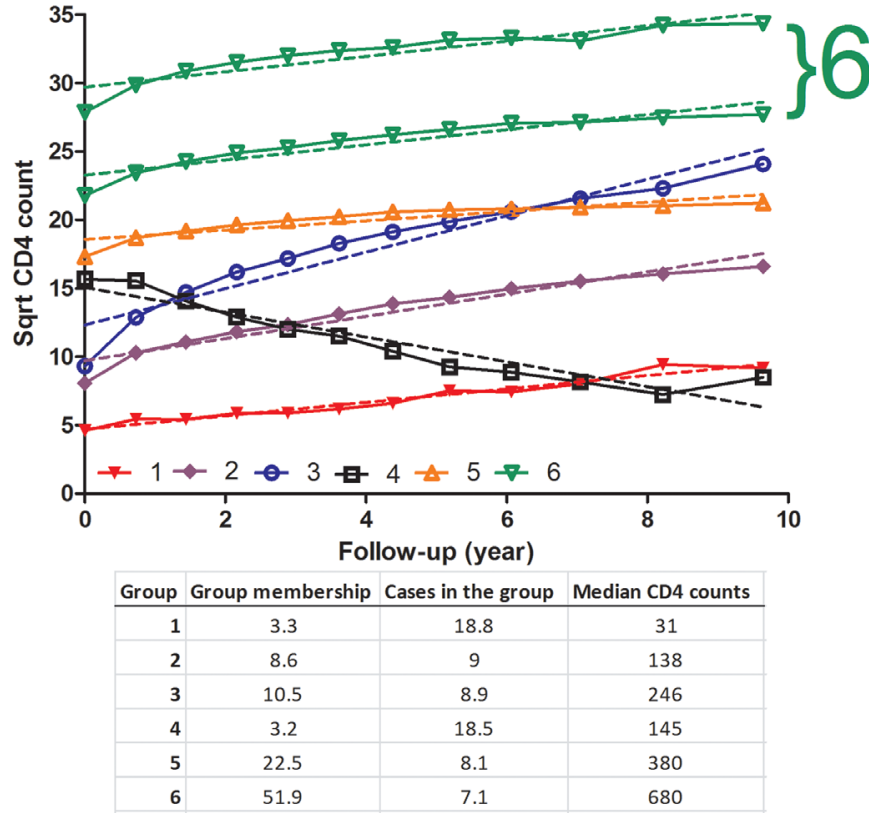

Figure 2 Trajectory CD4 counts for HSV-related anogenital ulcer disease (HAUD). Trajectory CD4 counts $>500$ cells/ $\mu \mathrm{L}$ are considered good immune recoveries and thus groups 6 and 7 were collapsed in logistic regression. Percentages of trajectory group membership (\%), cases in the group (\%), and median CD4 counts (cells/ $\mu \mathrm{L}$ ) of each trajectory group were given accordingly (solid line: direct connection between adjacent CD4 counts; dash line: modelled CD4 count trajectory). HAUD, herpetic anogenital ulcer disease; HSV, herpes simplex virus.

cohort consisted of $22.7 \%$ women; however, they contributed to $35.5 \%$ of the total incident HAUD cases (table 1). This corroborates with most published studies that suggest that HAUD are more likely to be clinically manifested in HIV-infected women than men. ${ }^{27}{ }^{28}$ In our study, women presented a 1.8 times higher IR of HAUD than men. Similarly, a study in Uganda estimated the prevalence of HAUD to be 1.4 times higher in women. HIV viraemia was observed to be higher among people with symptomatic HAUD (mean $\log _{10} \mathrm{VL}=4.4$ copies $/ \mathrm{mL}$ ) in that study. ${ }^{29}$ Patients with HAUD also had higher VL in our cohort, although the association was not statistically significant (mean $\log _{10}$ $\mathrm{VL}=4.8$ copies $/ \mathrm{mL}, \mathrm{p}=0.23$ ).

In the subanalysis of CD4 trajectory prior to the onset of incident HAUD, 3,947 PLWH had at least 3 CD4 examinations during the follow-up and were eligible for further analysis (retention rate $=90.9 \%$ ). Median CD4 count and CD4 count trajectory demonstrated strong associations with HAUD. Although other studies found that low nadir CD4 counts might lead to high risks of HSV-2 infections, ${ }^{930}$ no clinically presented HAUD have been directly linked with low nadir CD4 counts, but we observe that association in the current study (table 2).

In spite of similar significant associations observed between median CD4, trajectory CD4 groups with incident HAUD, the interpretations of these two measures could be very different. For example, two subjects with opposing trajectories could possess the same median CD4 count. Therefore, using a single (eg, median) CD4 count could result in misclassification and bias. For example, the median CD4 counts of subjects in trajectory groups 2 and 4 were 138 and 145 cells $/ \mu \mathrm{L}$ (figure 2), respectively. Therefore, both groups' median CD4 counts belonged 
to CD4 group $<200$ cells/ $\mu \mathrm{L}$. However, groups 2 and 4 had opposing trajectories: a steady increase in CD4 count in group 2, and a decline in group 4 . This resulted in about a $76 \%$ increase in the odds of groups 4 than 2 in both M1 and M2 (table 2; figure 2). Although the two group median CD4 counts were less than 200 cells/ $\mu \mathrm{L}$ only trajectory CD4 counts were capable of differentiating the odds.

HSV is not an oncogenic virus and does not generally lead to any fatal disease sequelae. Thus, preliminary studies have usually focused on its serological impacts on PLWH. Implementation of serological screening programme is debatable. In this study, we used a clinical cohort, and hence, all diagnoses were made following the standard clinical protocol for symptomatic HAUD. It is not recommended for general populations with asymptomatic HAUD to receive serologic HSV tests, ${ }^{31}$ but typespecific routine serological HSV screening for PLWH may also be considered. ${ }^{32}$ According to the Screening for Genital Herpes Simplex: Brief Update for the US Preventive Services Task Force, to date, no studies show that screening HSV-infection using serological tests reduced the occurrence of symptomatic HAUD. Additionally, no risk factors were used as the criteria for selective screening. The Task Force recommends against routine anogenital HSV screening in adults. ${ }^{33}$ A previous study suggested that in USA, the direct medical costs of HAUD ranged between $\$ 283$ million and $\$ 984$ million, and the indirect production loss due to HAUD could reach $\$ 214$ million. ${ }^{34}$ Even though the economic burden caused by HAUD seems striking, it is unclear to what extent the routine HSV screening is applied in HIV clinical settings.

We are aware of several limitations of the study. For example, only a very small portion $(2.6 \%)$ of the HAUD cases in the study received HSV-related serological tests. Thus, it is not possible to elaborate the specific HSV- type in the cases. The HAUD diagnoses were mainly based on physical presentations of ulcers clinically and as noted by the physician in the medical chart. However, this is a routine practice in the HIV specialised clinic and laboratory confirmation of HAUD is not considered necessary. Second, we did not include cART and other therapies in the analysis. Our research interest is to assess whether using trajectory CD4 groups would predict the onset of HAUD more precisely than the traditional one single CD4 count. CD4 count is the main immunological outcomes of treatment and could potentially account for issues with therapeutic data in relation to effectiveness and adherence. Additionally, over a 12-year follow-up, it is not uncommon for patients to go through different cART regimen, and hence, categorising cART is challenging. Thus, this variable was not used.

The southeastern US region bears a heavy public health burden of HIV, STIs and related STDs. ${ }^{35}$ HAUD even in patients with HIV is largely understudied and few studies have estimated the overall prevalence of HAUD but the incidence is still mostly not reported. We are aware that the current study underestimated the actual numbers of HAUD cases because we only analysed actual clinical patients with symptomatic HAUD. There is no routine protocol for HAUD screening and HAUD diagnoses were made mostly when patients chose to seek medical attention in response to HAUD-related symptoms, such as presentation of ulcers and self-reported pain in anogenital tracts. In other words, if patients prefer not to discuss with doctors, they would not have been diagnosed. In this context, HAUD might have been overlooked among PLWH in real-life.

Different patterns of CD4 trajectories were associated with onset of HAUD. No prior studies used CD4 trends to assess the risk of HAUD. In the present study, we demonstrated that using one single-CD4 test could lead to bias in risk assessment. Longitudinal CD4 counts are often available in EHR as part of the routine HIV-care for PLWH. Thus, there is no extra cost or protocol needed for data collection. Even though implementing universal HAUD screening does not seem possible at the moment, using CD4 trajectory could take advantage of the existing clinical information to inform physicians of high risk population that may require attention for HAUD screening and treatment.

\section{Key messages}

- Women living with HIV have higher risks of developing incident herpetic anogenital ulcer disease (HAUD) than men living with HIV.

- Trajectory CD4 counts are able to predict the risk of incident HAUD more precisely than using one single CD4 measure.

- Although mandatory anogenital herpes simplex virus screening is not recommended, using trajectory CD4 counts may be a useful clinical tool to assess and target the high risk population of HAUD in people living with HIV.

Correction notice This article has been corrected since it first published. The provenance and peer review statement has been included.

Handling editor Jonathan Ross

Acknowledgements We thank all study patients from the UAB 1917 Clinic. We also thank the UAB Research and Informatics Service Center (RISC) for data access (https://www.uab.edu/medicine/1917cliniccohort/).

Contributors YY, GAB and SS conceived the study. HW participated in statistical approach. YY processed and analysed the data. YY and SS interpreted the data and wrote the manuscript. All authors have reviewed and approved the manuscript.

Funding The authors have not declared a specific grant for this research from any funding agency in the public, commercial or not-for-profit sectors.

Competing interests None declared.

\section{Patient consent for publication Not required.}

Ethics approval The study was approved by the UAB Institutional Review Board for Human Use (IRB-170329001) and performed in accordance with the ethical guidelines of the Declaration of Helsinki. All informed consents were signed by the patients. Animals were not used in the study.

Provenance and peer review Not commissioned; externally peer reviewed.

Data availability statement Data are available on reasonable request. The data used for the manuscript is available through the Research and Informatics Service Center (RISC) at the University of Alabama at Birmingham (https://www.uab.edu/ medicine/1917cliniccohort/).

Open access This is an open access article distributed in accordance with the Creative Commons Attribution Non Commercial (CC BY-NC 4.0) license, which permits others to distribute, remix, adapt, build upon this work non-commercially, and license their derivative works on different terms, provided the original work is properly cited, appropriate credit is given, any changes made indicated, and the use is non-commercial. See: http://creativecommons.org/licenses/by-nc/4.0/.

\section{ORCID iD}

Sadeep Shrestha http://orcid.org/0000-0002-7002-357X

\section{REFERENCES}

1 Groves MJ. Genital herpes: a review. Am Fam Physician 2016;93:928-34.

2 Schacker T, Ryncarz AJ, Goddard J, et al. Frequent recovery of HIV-1 from genital herpes simplex virus lesions in HIV-1-Infected men. JAMA 1998;280:61-6.

3 Fleming DT, McQuillan GM, Johnson RE, et al. Herpes simplex virus type 2 in the United States, 1976 to 1994. N Eng/ J Med 1997;337:1105-11.

4 Dillon SM, Cummings M, Rajagopalan S, et al. Prospective analysis of genital ulcer disease in Brooklyn, New York. Clin Infect Dis 1997;24:945-50.

5 DiCarlo RP, Martin DH. The clinical diagnosis of genital ulcer disease in men. Clin Infect Dis 1997;25:292-8.

6 Gottlieb SL, Douglas JM, Schmid DS, et al. Seroprevalence and correlates of herpes simplex virus type 2 infection in five sexually transmitted-disease clinics. J Infect Dis 2002;186:1381-9. 
7 Augenbraun M, Feldman J, Chirgwin K, et al. Increased genital shedding of herpes simplex virus type 2 in HIV-seropositive women. Ann Intern Med 1995;123:845-7.

8 Schiffer JT, Swan DA, Magaret A, et al. Mathematical modeling predicts that increased HSV-2 shedding in HIV-1 infected persons is due to poor immunologic control in ganglia and genital mucosa. PLoS One 2016;11:e0155124.

9 Patel $\mathrm{P}$, Bush T, Mayer $\mathrm{KH}$, et al. Prevalence and risk factors associated with herpes simplex virus- 2 infection in a contemporary cohort of HIV-infected persons in the United States. Sex Transm Dis 2012;39:154-60.

101993 revised classification system for HIV infection and expanded surveillance case definition for AIDS among adolescents and adults. MMWR Recomm Rep 1992;41:1-19.

11 Moir S, Chun T-W, Fauci AS. Pathogenic mechanisms of HIV disease. Annu Rev Pathol 2011;6:223-48.

12 Chandrakala C, Parimalam K, Wahab A, et al. Correlating CD4 count with mucocutaneous manifestations in HIV-positive patients: a prospective study. Indian J Sex Transm Dis AIDS 2017;38:128-35.

13 Vergara-Ortega DN, Sevilla-Reyes EE, Herrera-Ortiz A, et al. Real time PCR to evaluate HSV-2 shedding from anal and genital samples among men who have sex with men, living with HIV. J Med Virol 2018;90:745-52.

14 Lange CG, Lederman MM, Medvik K, et al. Nadir CD4+ T-cell count and numbers of CD28+ CD4+ T-cells predict functional responses to immunizations in chronic HIV-1 infection. AIDS 2003;17:2015-23.

15 Psomas CK, Barber TJ, Rutsaert S. Highlights from the 9th IAS conference on HIV science, 23-26 July 2017, Paris, France. J Virus Erad;2017:242-9.

16 Willig JH, Aban I, Nevin CR, et al. Darunavir outcomes study: comparative effectiveness of virologic suppression, regimen durability, and discontinuation reasons for three-class experienced patients at 48 weeks. AIDS Res Hum Retroviruses 2010;26:1279-85.

17 Mugavero MJ, Lin H-Y, Allison JJ, et al. Failure to establish HIV care: characterizing the "no show" phenomenon. Clin Infect Dis 2007;45:127-30.

18 Corey L, Adams HG, Brown ZA, et al. Genital herpes simplex virus infections: clinical manifestations, course, and complications. Ann Intern Med 1983:98:958-72.

19 Kimberlin DW, Rouse DJ. Clinical practice. Genital herpes. N Engl J Med 2004:350:1970-7.

20 Joinpoint Regression Program. Version 4.3.1.0. National Cancer Institute 2016.
21 Ye Y, Burkholder GA, Wiener HW, et al. Comorbidities associated with HPV infection among people living with HIV-1 in the southeastern US: a retrospective clinical cohort study. BMC Infect Dis 2020;20:144.

22 Nagin DS, Jones BL, Passos VL, et al. Group-Based multi-trajectory modeling. Stat Methods Med Res 2018;27:2015-23.

23 Lange N, Carlin BP, Gelfand AE. Hierarchical Bayes models for the progression of HIV infection using longitudinal CD4 T-cell numbers: rejoinder. J Am Stat Assoc 1992;87:631.

24 Mcneil AJ, Gore SM. Statistical analysis of zidovudine (AZT) effect on CD4 cell counts in HIV disease. Stat Med 1996;15:75-92.

25 Lok JJ, Bosch RJ, Benson CA, et al. Long-Term increase in CD4+ T-cell counts during combination antiretroviral therapy for HIV-1 infection. AIDS 2010;24:1867-76.

26 Obirikorang C, Quaye L, Acheampong I. Total lymphocyte count as a surrogate marker for CD4 count in resource-limited settings. BMC Infect Dis 2012;12:128.

27 Celum $C$, Levine R, Weaver $M$, et al. Genital herpes and human immunodeficiency virus: double trouble. Bull World Health Organ 2004;82:447-53.

28 Celum C, Wald A, Lingappa JR, et al. Acyclovir and transmission of HIV-1 from persons infected with HIV-1 and HSV-2. N Engl J Med 2010;362:427-39.

29 Gray RH, Li X, Wawer MJ, et al. Determinants of HIV-1 load in subjects with early and later HIV infections, in a general-population cohort of Rakai, Uganda. J Infect Dis 2004;189:1209-15.

30 Ameli N, Bacchetti P, Morrow RA, et al. Herpes simplex virus infection in women in the WIHS: epidemiology and effect of antiretroviral therapy on clinical manifestations. AIDS 2006:20:1051-8.

31 Why have false positive tests been used as an argument against routine testing for genital herpes, but not for other STDs, which can also have false positives? CDC 2007.

32 Guidelines for the prevention and treatment of opportunistic infections in adults and adolescents with HIV. AIDS info, US Department of Health and Human Services 2019.

33 , Bibbins-Domingo K, Grossman DC, et al, US Preventive Services Task Force. Serologic screening for genital herpes infection: US preventive services Task force recommendation statement. JAMA 2016:316:2525-30.

34 Szucs TD, Berger K, Fisman DN, et al. The estimated economic burden of genital herpes in the United States. An analysis using two costing approaches. BMC Infect Dis 2001;1:5.

35 HIV in the southern United States. CDC, HIV in the South Issue Brief 2019. 